\title{
LAS CONVERSACIONES SIGUEN A PESAR DEL RUIDO' DEDICADO A JOHN V. MURRA
}

\author{
Calogero M. Santoro ${ }^{1,2}$
}

\begin{abstract}
Conocí a John Víctor Murra, sin que llegáramos a cruzar palabra en julio de 1973, en plena campaña de socialización de su modelo de verticalidad y cuando pregonaba, además, la necesidad de historiar "lo andino" a partir de fuentes variadas de información, como la documentación de origen colonial y, mientras más tempranas mejor, las etnográficas y las arqueológicas. Estábamos en medio del crudo invierno de ese año y tenía como escenario el Primer Congreso del Hombre Andino que itineró por Arica, Iquique y Antofagasta, una idea de Lautaro Núñez, presidente de la reunión, de trashumar el evento por el desierto del norte de Chile. Esto de organizar reuniones de largo aliento con observación de campo no era ajeno a Murra. De hecho, el Congreso en Arica sirvió de nodo para una parada de un seminario de campo que llevaba a cabo junto con Luis G. Lumbreras alrededor del lago Titicaca (Murra 1984).

Posiblemente la experiencia del Congreso fue integral para Murra, ya que no sólo se discutió acerca de los logros del "hombre" andino con sus proyecciones y significados en el presente, sino también cómo las soluciones andinas habían alcanzado hasta los inhóspitos parajes del desierto de Atacama. Pero, además, porque se enfrentaron perspectivas contrapuestas, reflejo del complicado ambiente político del país y del continente en general, a tal punto que el Congreso fue interrumpido en Antofagasta por el "tanquetazo", un intento anticipatorio de las fuerzas armadas chilenas por derrocar al gobierno socialista de Salvador Allende.

Este clima bélico no era extraño a la experiencia de Murra; "fue así como aprendí el castellano", me diría años más tarde en algunas de las conversaciones que tuvimos en Arica o en Ithaca. Con ello se refería a su paso por el ejército Republicano de España (ver Castro et al. 1999; Mintz 2009, su compañero de filas, en este número de Chungara),
\end{abstract}

cuyos pormenores escuché en más de una de esas conversaciones. Desde los años setenta Murra visitó varias veces Arica, para conectarse con los colegas, las instituciones y amigos que se dedicaban de alguna manera a los estudios andinos. Su última estadía de tres semanas ocurrió en el invierno de 1995 que sirvió entre otras cosas para tratar de resucitar su idea de radicarse en la ciudad, pero al final concluía resignado "es demasiado tarde", y evocaba una imagen de sí mismo camino a casa, al final del día, con un pescado, comprado en la caleta de pescadores de Arica y un diario bajo el brazo. En ese invierno, nos reuníamos a diario a comer y conversar, un ritual que comenzaba con una llamada al hotel del centro de la ciudad, donde recibía pequeñas atenciones especiales que le gustaba disfrutar, como que le fueran a comprar un periódico de la capital a mediodía, o que le trajeran algo de comer sin que lo hubiera pedido o que incluso se preocuparan de medicinarlo cuando lo veían medio afectado de salud. Eso ayudaba a romper su dictamen perentorio del día anterior de que no lo llamara, ni lo fuera a buscar, que se quedaría sólo en el hotel, pero invariablemente contestaba a mi saludo vía telefónica con un: "vivo"... y luego silencio, que se rompía con mi invitación a comer y su respuesta: "páseme a buscar a las 7:30". A esa hora lo encontraba listo, arreglado con una boina, un paletó oscuro y una bufanda. La velada se animó varias noches sentados en el balcón del segundo piso de un pequeño restaurante en la calle principal, donde a Murra le gustaba sentarse para ver el fluir, el devenir de la ciudad mientras hilvanaba historias, varias de ellas conocidas (Castro et al. 2000; Rowe 1984).

En una de esas conversaciones me contó la anécdota de su máquina de escribir, que relaté a los colegas Vicki Castro, Frank Salomon, Jorge Hidalgo y Carlos Aldunate, reunidos el 12 de agosto

\footnotetext{
1 Instituto de Alta Investigación, Departamento de Antropología, Universidad de Tarapacá, Arica, Chile. calogero_santoro@yahoo.com

2 Centro de Investigaciones del Hombre en el Desierto, Arica, Chile.
} 
de 2008 en el Museo Chileno de Arte Precolombino en Santiago, lo que resultó ser desconocido para ellos, de allí la idea de socializarlo en este homenaje. Este suceso refleja, por un lado, su actitud liberal respecto de sus relaciones de pareja y, por otro, su preocupación de escribir con la grafía original las lenguas que manejaba con gran elegancia, complejidad gramatical y fonética. Desde muy joven, decía, dominaba varios idiomas: rumano, francés, ruso, alemán, cuyas tipografías eran difíciles de controlar en un solo instrumento tecnológico, mecánico, antes de la aparición de los ordenadores. De la tecnología moderna, Murra puso al servicio de su oficio de escribir dos artefactos que le fueron inseparables y que se transformaron en iconos fundamentales en su casa de Dryden Rd 515, en Ithaca, New York: la fotocopiadora y su máquina de escribir. Éstas eran para Murra como el escudo y la lanza del Quijote de la Mancha, sus únicos atuendos intelectuales, todo lo demás radicaba en su reconocida genialidad, memoria e inteligencia (ver Salomon 2010 en este número).

La máquina de escribir Olivetti que muchos conocieron en su casa a pocas cuadras de McGraw Hall donde ha funcionado el departamento de Antropología de la Cornell University, fue el regalo de una ex novia, quien un día junto con anunciarle que se casaba con un joven italiano-americano le pidió que fuera su consorte en el camino al altar. Murra accedió gustoso y previo a la boda tuvo la ocasión de conocer al novio, empleado de la empresa Olivetti. Éste enterado de su oficio le ofreció una máquina de escribir personalizada, lo que le dio la oportunidad de conseguir un artilugio posiblemente único en el mundo, que tenía las grafías para los idiomas que usaba (Figura 1).

Para Murra contar con esta herramienta de trabajo fue tan importante como la máquina fotocopiadora Xerox. Estos fueron dos puntales tecnológicos que le permitieron, por un lado, escribir en las tres lenguas que usó para comunicar sus ideas, español, francés e inglés, como así también en rumano a su hermana Ata Iosifescu².

Con la fotocopiadora multicopiaba no sólo sus manuscritos en distintas etapas de elaboración, sino también cuanto material que consideraba pudiera ser de interés a algún colega de su amplia red de contactos alrededor del mundo. Pero no sólo de textos históricos acompañaba su correspondencia, también copiaba chistes del New Yorker que remitía con comentarios como aquella vez que consiguió

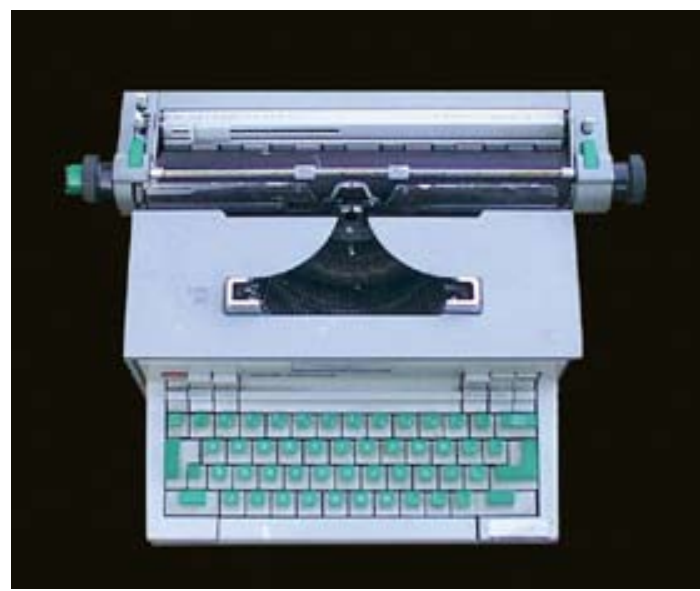

Figura 1. Máquina, preparada especialmente, para escribir con las grafías de los idiomas que usaba el Dr. John V. Murra (fotografía gentileza de Judy Willis y David Block ${ }^{3}$ ).

una tira cómica de un recuadro con la caricatura de un personaje que rodaba por una escalera, cosa que le aconteció en el años 1999. La fotocopia venía con una flecha y un comentario "así me callí(sic) yo".

Por varios años contó con un servicio técnico superb, superlativo que usaba para cuestiones que realmente satisfacían plenamente sus expectativas, tanto para el mantenimiento de la máquina de escribir, puesto que el regalo del novio italiano venía con "perseguidora", vale decir, quedó con los contactos para que de la Olivetti vinieran por revisiones rutinarias reparaciones de algún tipo gastado, o mecanismos atascados. Lo mismo le ocurría con sus máquinas Xerox, las arrendaba, y ello incluía servicio técnico cada cierta cantidad de copias y la renovación de la misma por una de nueva generación.

En la primavera del 2001 de visita en su casa de Dryden, cuando ya no vivía allí sino en un departamento en Buffalo Street en el centro de Ithaca, se lamentó que ya no ofrecieran ese servicio de arriendo de máquinas de fotocopiar y que a cambio había que comprar trastos que funcionaban por poco tiempo y con sistemas operatorios digitales y no mecánicos como las antiguas.

Sentí que junto con irse esa tecnología se había ido también toda una era de escribir y producir textos científicos, históricos, periodísticos. Aparte de las máquinas se lamentaba que "la vista ya no me acompaña y la memoria ya no es igual", pero más que una limitante física me impresionó que su declaración denotaba una suerte de sensación de soledad: "es que escribir solo es muy aburrido, 
uno tiene que conversar de otras cosas". Traté de convencerlo que buscara a alguien que lo ayudara como secretaria(o), privada(o), y me decía "aquí nadie sabe bien castellano". Me habló, sin embargo, de una señora del "campo" que venía de vez en cuando a verlo. Ella tiene aspiraciones intelectuales, quiere y tiene condiciones para escribir poesía en medio de una vida rural y con varios hijos a cuesta y eso le emocionaba y llenaba de ternura.

Visitar su casa de Dryden Rd el 2001 era tormentoso, le preocupaba el destino de pequeños detalles como el dibujo pintado a escala de un quipu camayoc en un muro del comedor de la casa, una cortina artesanal que le había hecho y regalado Ángel Palerm, uno de sus amigos más entrañables, que lamentaba que se hubiera muerto tan joven, que estaba en un ventana alargada junto al descanso de la escalera que subía al segundo piso y miles de papeles, cartas, objetos, como la fotocopiadora que había quedado varada allí en la mesa del comedor y libros, varios de ellos regalos de los autores con sentidas dedicatorias, o copias de manuscritos originales de otros colegas. "Todo esto va a desaparecer el día que me vaya definitivamente". Me entrevisté entonces con David Block, bibliotecario para asuntos de América Latina de la Universidad de Cornell y en quien Murra confiaba. Le traspasé esta preocupación y convenimos que si Cornell no se hacía cargo de esta "cultura material" ligada directamente a la historia de Murra en esta Universidad, su vaticinio se haría realidad. Cuarenta y ocho horas más tarde y mientras almorzábamos en un restaurante, que había sido una "picada" de comida vietnamita de su época de profesor en Cornell, me contó entusiasmado que David lo había llamado para retomar una campaña de inventario de los bienes y documentos (ver Block 2009; Friedrich 2005). Un año antes, el 1 de agosto de 2000, me había escrito: "Estuve en mi casa el otro día, con nuestro Bibliotecario (D. Block) para hablar de la suerte de lo q. queda en mi biblioteca".

La máquina de escribir se conserva hoy día en la Olin Library de Cornell, con otras pertenencias de John Murra, y agradezco la gentileza de David por la fotografía que ilustra este recuerdo de "...conversaciones [que] siguen a pesar del ruido", parafraseando su dedicatoria al libro Nispa Ninchis, lanzado en el Instituto de Estudios Peruanos, Lima abril del año 2000 (Figura 2).

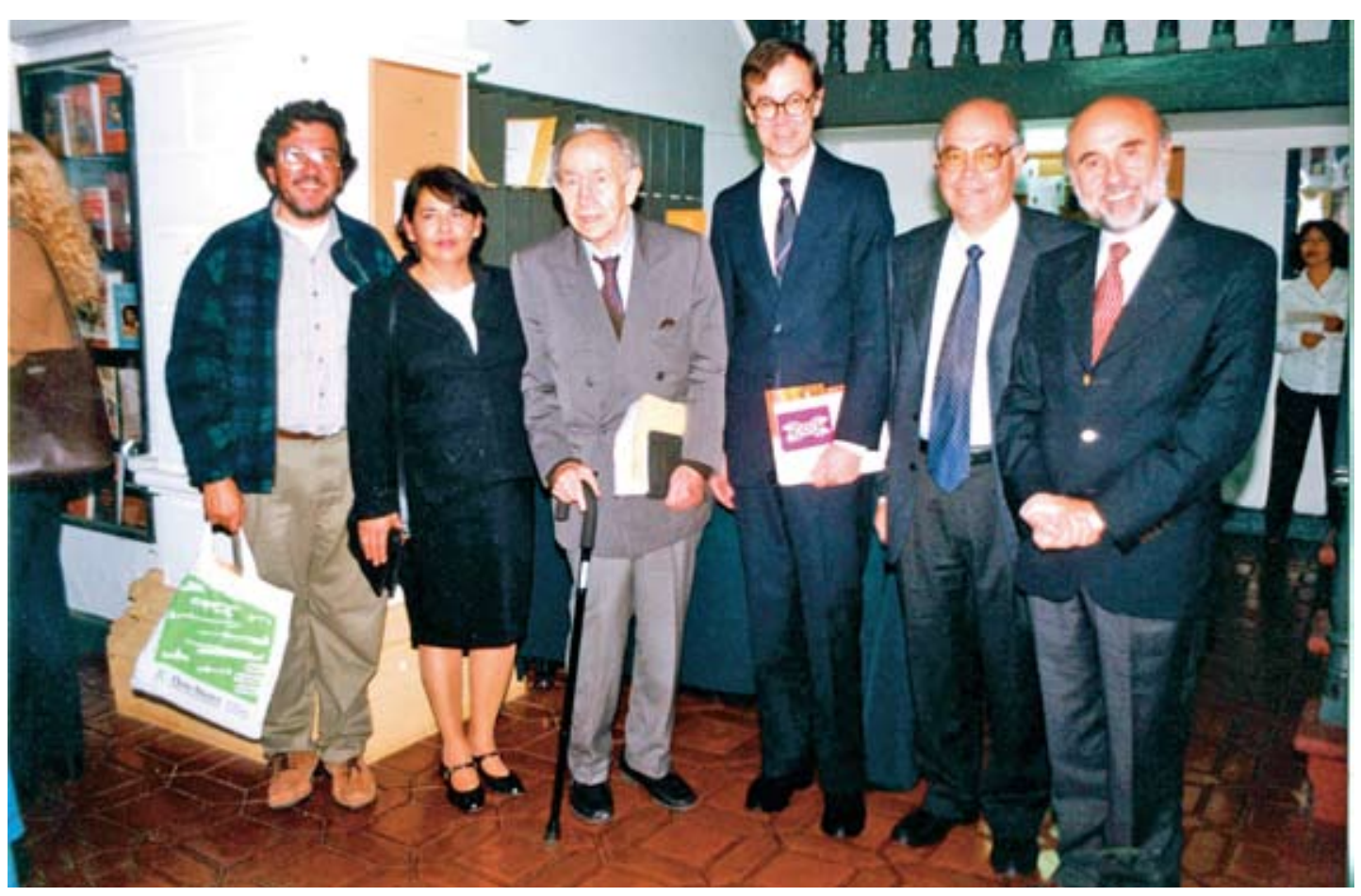

Figura 2. Celebración de la presentación del libro Nispa Ninchis en el Instituto de Estudios Peruanos, Lima, abril del año 2000 (de derecha a izquierda: Carlos Aldunate, Jorge Hidalgo, Craig Morris ${ }^{\dagger}$, John Murra ${ }^{\dagger}$, Victoria Castro y Calogero Santoro, foto autor desconocido). 


\section{Referencias Citadas}

Block, D.

2010 John V. Murra bibliografía. Chungara Revista de Antropología Chilena 42:141-145.

Castro V., C. Aldunate y J. Hidalgo, editores

2000 Nispa Ninchis. Decimos Diciendo. Conversaciones con John Murra. Instituto de Estudios Peruanos, Institute of Andean Research, Lima.

Friedrich, A.

2005 Register to the Papers of John Victor Murra. National Anthropological Archives, Smithsonian Institution, Washington D.C.
Mintz, S.

2010 Remarks in memory of John Victor Murra. Chungara Revista de Antropología Chilena 42:59-61.

\section{Rowe, J.H.}

1984 An Interview with John V. Murra. Hispanic American Historical Review 64:633-653.

Salomon, F.

2010 Murra en la selva de paja. Chungara Revista de Antropología Chilena 42:13-18.

\section{Notas}

1 Dedicatoria de John V. Murra al libro Nispa Ninchis, Lima 2000 (Castro et al. 2000).

2 En un sentimiento de gran admiración por su hermano, Ata Iosifescu tradujo su tesis doctoral sobre La Organización Económica del Estado Inca, que apareció bajo el título de Civilizatie Inca: Organizarea Economica A Statului Incas, publicado por Bucuresti, Editura Stiintifica si Enciclopedica,
1987, en Bucarest. De acuerdo a Murra el libro fue un éxito por lo que se re-imprimió varias veces: "nunca un libro mío se imprimió tantas veces", me dijo en más de una oportunidad.

3 Agradezco a Reiko Ishihara por la edición digital de esta imagen. 